\title{
Architecture is Competition
}

\author{
BRIAN STRAWN \\ University of Hawaii At Manoa
}

KARLA SIERRALTA

University of Hawaii At Manoa

\begin{abstract}
ARCHITECTURE IS COMPETITION.
Student competitions, professional competitions, open competitions, single stage, multi-stage, ideas competitions, international competitions, local contests, invited competitions, nominations, RFQ's, RFP's, peer-reviews, fellowships, awards, grants...we are always competing.
\end{abstract}

As competition entrants, advisers to students, jurors, and organizers, our small, two-person studio has been involved in over 40 architectural design competitions in the past fifteen years.

To us, competitions are a framework for architectural education, practice, and advocacy. We believe competitions:

\section{EVEN THE PLAYING FIELD}

Competitions are an opportunity to reach a broader audience, in anonymity, detached from name, gender, school prestige, nationality, personal brand, or architectural lineage.

\section{ENCOURAGE CRITICAL NARRATIVES}

Competitions are a venue for research, speculation, and discovery. They allow us to question our reality, offer a way to explore beyond established boundaries and functional constraints. Competitions serve as a platform to envision the future.

\section{EXPOSE US TO NEW PROBLEM FIELDS}

Architecture can be hyper-specialized. Competitions permit exploration of new topic areas and typologies not confronted in daily practice.

\section{BUILD NEW COMPETENCIES}

Participating in competitions facilitates learning. They are safe places to test drive advanced software, practice new tools of representation, and gain exposure to industry best practices.

\section{ACCELERATE THINKING}

Short timeframes necessitate a charette approach, require a clear point of view, focus efforts toward big ideas, and hone time management skills. Competitions build tacit knowledge and design-muscle memory.

\section{EMPOWER ARCHITECTS}

Competitions are space for recovering our voice as designers in a deconstructing, fragmented discipline and allow us to reclaim participation in the genesis of ideas. 


\section{Architecture is Competition}

COMPETITORS

ORGANIZERS / CURATORS

ACADEMIC ADVISORS
9/11 Memorial Phase I/ Finalist, Exhibition 2003

ACSA Pavilion Finalist, Exhibition 2018

Chicago Prize "Urban Water Tanks" Selected for Exhibition 2005

C2C Home Selected for Exhibition 2004

Green Tent First Place, Exhibition 2004

History Channel's "City of the Future" IBM Engineering Innovation Award, Exhibition 2006 McCormick Tribune Freedom Museum Sculpture Phase // Finalist, Exhibition 2005 New Orleans Sustainable Housing Design Competition Notable Entry Award 2006 Olympic Landmark for Paris 2012 Notable Entry Award, Exhibition 2004

The Shining Maze Finalist 2015

Architecture for Humanity \& Nike "Community Center" 2010

Architecture for Humanity "Slyathemba Youth Sports Facility" 2004

Architecture for Humanity "Youth Sports Facilities for Africa" 2008

Calgary Artcity 2006

Cheogna City Tower Design 2008

Dwell Playhaus 2011

Flight 93 National Memorial 2005

Jardins de Metis International Garden Festival 2008

Jardins de Metis International Garden Festival 2009

Portland Housing Competition 2007

Ragdale Ring 2016

Re:Vision Dallas 2009

Rio City Tower 2009

Tsunami Memorial 2005

Building Voices Competition \& Exhibit 2017

Building Voices "Honolulu Connects" Competition \& Exhibit 2018

Burnham Prize "Next Stop" Competition \& Exhibit 2013

Chicago Prize "Future Prentice" Competition \& Exhibit 2012

Currencies of Architecture Exhibit 2015

Emerging Visions Competition \& Exhibit 2014

ACSA/AISC Steel Student Design Competition HM 2010

Building Voices Second Place, Third Place, HM, HM, Citation, Citation, Citation 2017

ComEd Student Design Challenge First Place 2012

Metal Construction Association Student Design Competition Third Place, HM 2006

SOFA Design-Build Installation 2014

SOFA Design-Build Installation 2015

AlA Houston Design Awards 2007

Art Institute of Chicago, Schiff Foundation Fellowship 2011

ASLA Hawai'i Design Awards 2018

Black Spectacles "The Un-Competition Project" 2012

Building Voices "Honolulu Connects" 2018

Chicago Architectural Club "Emerging Visions" 2014

University of Hawai'i "Ala Wai Challenge" 2017

University of Illinois at Urbana-Champaign "Green Re-scheme" 2010 